\title{
Formulation of a behavior system for sexual conditioning
}

\author{
MICHAEL DOMJAN \\ University of Texas, Austin, Texas
}

\begin{abstract}
Empirical and conceptual developments that led to the formulation of a behavior system for the sexual conditioning of male Japanese quail are described. Initial efforts concentrated on conditioning with localized conditioned stimuli and on identifying behavioral indices of conditioning. Later, learning about species-typical cues and about contextual cues was also explored, and it became evident that different types of cues control different aspects of sexual behavior. The results were used to formulate a behavior system containing both response and stimulus dimensions. In this system, contextual cues and local cues are assumed to elicit only general search behavior unconditionally. In contrast, unconditioned responses to species-typical cues of a female quail include general search, focal search, and copulatory behavior. General search, focal search, and copulatory behavior can become conditioned to local cues. Conditioning can also modify focal search behavior elicited by species-typical cues and can result in various modulatory influences between different types of stimuli. The behavior system approach provides a framework for organizing the diverse sexual conditioning effects and suggests future directions for investigation.
\end{abstract}

As the papers in this symposium illustrate, comprehensive understanding of how behavior develops and is shaped by experience is facilitated by considering how specific action patterns are organized into systems of behavior. The investigation of a behavior system may be conducted using either an analytic strategy or a synthetic strategy. In the analytic strategy, one starts with a theory or hypothesis about how the behavior system is organized and then proceeds to test empirical implications of this hypothesis. In the synthetic approach, in contrast, one first obtains information about how animals accomplish a particular biological task such as reproduction or foraging for food. This information is then used to figure out how the activity is organized.

About ten years ago, my students and I embarked on an investigation of the mechanisms of sexual learning. Although numerous demonstrations of sexual learning effects were available at the time (see Domjan \& Hollis, 1988 , for a review), the available evidence, with few exceptions, was demonstrational and did not provide much insight into the mechanisms of sexual learning. Given the poorly developed status of the area, we decided to pursue a research strategy that was primarily synthetic rather than analytic. In this paper I will describe the steps we took in this synthetic research strategy, as an illustra-

The preparation of the manuscript and much of the research was supported by National Institute of Mental Health Grant MH39940 to Michael Domjan. Many research associates, including C. Akins, L. Crawford, G. Gutiérrez, S. Hilliard, K. Holloway, and F. Köksal, contributed to the ideas presented in this paper. I am grateful to them all. Correspondence concerning this article should be addressed to Michael Domjan, Department of Psychology, University of Texas, Austin, TX 78712 (e-mail: domjan@psyvax.psy.utexas.edu). tion of how the study of learning can be profitably extended into new areas without detailed preconceptions.

\section{GETTING STARTED}

The first step was to select a species and a behavioral situation to study. We chose an avian species because our long-term goals include comparing sexual learning in species with contrasting mating systems (see Domjan \& Hollis, 1988). Birds afford rich opportunities for such comparative research. We also wanted a species whose sexual behavior can be easily observed and that can be comfortably maintained in the laboratory at reasonable cost. Finally, we wanted a species in which some evidence of sexual learning had already been reported. These considerations led us to the male Japanese quail (Coturnix japonica). The Japanese quail is a popular model system in poultry science research (see Kovach, 1974), and its sexual behavior has been the subject of extensive neurohormonal investigations (see reviews by Adkins-Regan, 1983; Balthazart, 1990; Balthazart \& Schumacher, 1984, 1985).

Although our initial efforts were not guided by detailed hypotheses about sexual learning, we relied on basic concepts of Pavlovian conditioning. In Pavlovian conditioning, an initially ineffective stimulus [the conditioned stimulus (CS)] becomes associated with a biologically significant event [the unconditioned stimulus (US)] and comes to elicit conditioned responses relevant to that US. In our experiments, the unconditioned stimulus was always provided by giving sexually active male quail the opportunity to copulate with a sexually receptive female. The conditioned stimuli used included lights and various three-dimensional objects, contextual 
cues, and species-typical cues provided by the shape and plumage of quail.

\section{RESPONSE CONSIDERATIONS IN SEXUAL CONDITIONING}

Although learning is not always directly evident in the actions of an organism, a suitable indicant response is a prerequisite for the study of learning at the behavioral level. Therefore, our initial efforts focused on elucidating the types of responses subjects might perform as evidence of their sexual learning.

Sexual conditioning in male Japanese quail was first investigated by Farris (1967), who reported that male quail perform a courtship-like action pattern, the horizontal display, in response to a brief buzzer that is presented just before the introduction of a female bird into their cage. The conditioned behavior included stretching the head and neck forward and slightly downward in a horizontal position. Although Farris's experiment was fairly limited (only three subjects served in the experimental group and two birds served in a control group), it suggested that male quail can associate an arbitrary stimulus with access to a female and can perform a discrete and easily identified response to the conditioned stimulus.

In our initial studies (Domjan, Lyons, North, \& Bruell, 1986), we modified Farris's procedure in some ways. For example, we used much larger experimental chambers $\left(1.1 \mathrm{~m}^{2}\right.$, as compared with $\left.0.44 \mathrm{~m}^{2}\right)$, on the assumption that giving the birds more room would enable them to display a greater variety of responses. In addition, we used a visual CS (a red light near the door that provided access to a female bird) instead of a buzzer, so that the subjects would not be exposed to the conditioned stimulus when it was presented to other birds in the same room.

\section{Conditioning Approach and Social Proximity Behavior}

We followed Farris's lead and recorded a variety of behavioral responses (see Table 1, Domjan et al., 1986), including how much time the subjects spent in a small area near the conditioned stimulus. In previous studies, we found that sexually experienced males tend to remain near, and in visual contact with, female quail (Domjan \& Hall, 1986). We thought that the male subjects may also approach and remain near a localized conditioned stimulus that signaled access to a female bird. This prediction was amply substantiated. In fact, the predominant conditioned response was approaching and remaining near the CS. We did not observe increases in the frequency of any other responses. Furthermore, contrary to the observations of Farris (1967), we witnessed the horizontal display much more often after the subjects finished copulating with a female rather than preceding copulation. Thus, the horizontal display appeared to be a reflection of a postcopulatory sexual refractory period rather than an aspect of precopulatory courtship behavior.
Another result of conditioning was that the subjects became faster at initiating copulatory behavior. Copulation in quail begins with the male grabbing the back of the female's head or neck with its beak. The latency of the grab response declined in both the experimental and the control groups. However, those subjects that received the CS paired with access to a female bird showed a significantly more rapid decline in their grab latency.

This first experiment provided several major findings that have to be considered in the formulation of a behavior system for sexual learning. The red-light CS was arbitrary to the sexual behavior system; it was unlike the species-typical cues of a female quail and did not elicit any sex-related responses unconditionally. The experiment demonstrated that such a localized arbitrary conditioned stimulus can come to elicit approach behavior but will not elicit the copulatory responses of grab, mount, and cloacal contact. These copulatory responses occurred only when a female quail was introduced. However, the arbitrary CS facilitated copulation with a female; it increased the effectiveness of female speciestypical cues in eliciting copulatory behavior.

\section{Conditioning of Copulatory Behavior}

The absence of copulation to the red-light CS used in our first study (Domjan et al., 1986) was not surprising because this CS did not provide the supporting stimulation that is no doubt necessary for the male to make grab, mount, and cloacal-contact responses. In a subsequent study (Domjan, O'Vary, \& Greene, 1988, Experiments 3 and 4), we employed as the arbitrary conditioned stimulus a soft, three-dimensional object made of cloth - a Pound Puppy manufactured by Tonka Toys. The toy was propped up in the posture of a female quail, to enable the male to grab and mount it. The conditioning procedure consisted of pairings of this object with the opportunity to copulate with a female quail. As conditioning proceeded, the subjects quickly came to approach and remain near the CS object. However, they never made grab, mount, or cloacal-contact responses.

The fact that the subjects rapidly came to approach and remain near the soft CS object but did not attempt to copulate with it suggests that the approach component of the sexual behavior sequence is more easily conditioned than copulatory contact responses. We have used a variety of conditioned stimuli, including a lighted pecking key, a wood block, a foam block with orange feathers, and a terrycloth object consisting of a vertical section the subjects could grab and a horizontal pad on which they could mount and make cloacal thrusts (Domjan et al., 1986; Holloway \& Domjan, 1993; Köksal, Domjan, \& Weisman, 1994). Conditioned approach developed within 10 trials with all of these kinds of stimuli. In contrast, copulatory contact responses rarely occurred. We were successful in conditioning copulatory responses only if the object that was used as the CS included some of the plumage and other features of a female quail (Domjan et al., 1988), at least initially (Domjan, Huber-McDonald, \& Holloway, 1992). 
The differential susceptibility to conditioning of approach and copulatory behavior is consistent with the characterization of behavior systems in classical ethological theory, whereby species-typical behavior was categorized as consisting of appetitive responses and consummatory responses. Appetitive responses were assumed to involve the search for sign stimuli. Upon encountering the relevant sign stimulus, the organism would then complete or consummate the species-typical behavior sequence. Each consummatory response was assumed to be strictly under the control of its particular sign stimulus. Consummatory behavior was characterized as "rigid" (Tinbergen, 1951, p. 105) and "automatically discharged" (Eibl-Eibesfeldt, 1970, p. 45). In contrast, appetitive behavior was assumed to be more variable and more easily modified.

In our sexual conditioning situations, approaching and remaining near a stimulus that signals access to a female may be considered appetitive behavior, whereas grab, mount, and cloacal-contact responses are consummatory responses. The differential susceptibility to sexual conditioning of these two categories of behavior is consistent with the claim that appetitive behavior is more modifiable and more flexible than consummatory behavior.

\section{Conditioning of General Search Behavior}

The above findings suggest that the behavior system for sexual conditioning should have at least two response categories-approach behavior and copulatory behavior. Results from a recent study of the effects of the CS-US interval on sexual conditioning (Akins, Domjan, \& Gutiérrez, 1994) suggest the need for an additional response category. Our initial experiments were conducted with delayed conditioning procedures in which each presentation of the CS ended with the release of a female quail (the US) and the CS-US interval was $30 \mathrm{sec}$ or less. Akins et al. also used delayed conditioning procedures, but the CS-US intervals that they tested were as long as $20 \mathrm{~min}$.

At first, Akins et al. (1994) only measured how much time the subjects spent near the CS. With this measure, conditioned responding quickly declined with increasing CS-US intervals, and no learning was evident with a 20-min delay between the onset of the CS and the onset of the US. However, incidental observations suggested that rather than approaching and remaining near the CS, the subjects increased pacing in the experimental arena during the 20-min CS-US delay.

The experimental chambers used by Akins et al. (1994) had twice the floor area of the chambers used in our other experiments. The CS and US were presented at one end of the $1.8 \mathrm{-m}$ long rectangular arena, enabling Akins et al. to distinguish between pacing near the CS and pacing in more remote areas of the test cage. Pacing behavior was quantified by counting how often the birds crossed in and out of a small area near the CS and how often they crossed between one half of the experimental chamber and the other. With a 1-min CS-US interval, the subjects increased their pacing near the CS and de- creased their crossings from one half of the chamber to the other. In contrast, with a 20-min CS-US interval, pacing increased between the two halves of the experimental chamber, but there was no increase in pacing near the CS.

The findings of Akins et al. (1994) are important because they demonstrate that sexual conditioning can occur with a CS-US interval as long as $20 \mathrm{~min}$. In addition, the results show that different types of conditioned behavior occur, depending on the CS-US interval. Evidently, precopulatory or appetitive sexual behavior takes at least two forms, one involving behavior localized near the CS and the other involving behavior that is not so stimulus bound. Borrowing terminology used to describe components of foraging behavior, approaching and pacing near the CS in anticipation of copulatory opportunity may be called focal search behavior. In contrast, locomotion over larger areas of the experimental chamber may be called general search behavior. General sexual search was activated by stimuli conditioned with a long CS-US interval, whereas focal sexual search was activated by stimuli conditioned with a short CS-US interval. These findings are similar to predictions made by Timberlake and Lucas (1989) concerning the conditioning of general and focal search behavior in a behavior system for foraging for food.

\section{STIMULUS CONSIDERATIONS IN SEXUAL CONDITIONING}

The importance of the nature of the eliciting stimulus in sexually conditioned behavior first became obvious to us when we encountered difficulties in conditioning copulatory responses. As noted earlier, in one of our initial experiments, the CS was a three-dimensional object, a stuffed toy dog. In principle, the CS object could provide the physical support needed for copulatory responses. However, it never came to elicit conditioned copulatory behavior, although it elicited conditioned approach (Domjan et al., 1988). The failure of the toy to elicit conditioned copulation could not be attributed to the fact that it was inanimate and unresponsive, since vigorous copulation can occur in response to an inanimate taxidermic model of a female quail (Domjan, 1990). Copulation can also occur in response to models in which the body of the female is replaced by a terrycloth mounting pad, leaving only the female's head and neck (Domjan, Greene, \& North, 1989), or in which the female's head and neck are replaced with a vertical terrycloth cylinder that the male can grab, leaving only the female's body for mounting and cloacal thrusts (Crawford \& Akins, 1993).

The above results suggest that at least some of the species-typical features of a female quail (shape and plumage) are necessary for the occurrence of copulatory responses. However, this does not mean that the effectiveness of the species-typical stimuli is unconditioned and not subject to learning. Tinbergen (1951) pointed out a long time ago that experiences common to all mem- 
bers of a species can lead to uniformity in their response to species-typical cues. Consistent with this suggestion, we have found that, in the Japanese quail, certain types of sexual responses to species-typical stimuli are a product of learning.

\section{Learning About Species-Typical Cues}

Our interest in the possibility that quail may learn about species-typical stimuli was aroused by incidental observations during studies of social proximity behavior (the tendency of quail to remain near each other). Male quail tend to approach and remain near a small window through which they can see a female, especially if they have had sexual experience with females in the test situation (Domjan \& Hall, 1986). Once subjects learn to approach and remain near females, they also approach and remain near a window through which they can see a male stimulus bird. However, responding to male stimulus birds declines if exposure to males is not paired with sexual reinforcement (Domjan \& Hall, 1986; Domjan \& Ravert, 1991).

Male quail appear to learn to discriminate the sex of other quail through differential sexual reinforcement (Nash, Domjan, \& Askins, 1989). Exposure to the visual cues of a female followed by copulatory opportunity results in increased and persistent responding to female cues. Such responding initially generalizes to cues provided by a male stimulus bird. Subsequent exposure to male cues without copulatory reinforcement produces a decline or extinction in responding to males. The final outcome is that the subjects approach and remain near females significantly more than they approach and remain near males (see also Nash \& Domjan, 1991).

\section{Modulation of Responses to Species-Typical Cues by Conditioned Stimuli}

The above studies illustrate that males can learn directly about the plumage and other species-typical features of other quail. Learning can also influence responses elicited by species-typical cues through modulatory processes. In particular, the effectiveness of species-typical cues in eliciting components of sexual behavior can be facilitated by arbitrary sexually conditioned stimuli.

We first observed conditioned modulation of copulatory responses to species-typical cues in our initial experiment on sexual Pavlovian conditioning in which a red light served as the CS (Domjan et al., 1986). The red-light CS did not come to elicit copulation directly; copulatory responses occurred only when a female quail was present. However, conditioning shortened the male's latency to copulate with the female. The red-light CS made female cues more effective in eliciting copulatory behavior.

We unexpectedly encountered another example of conditioned modulation of sexual behavior elicited by species-typical cues in an experiment that was intended to explore an object-learning model of how animals might learn directly about the species-typical features of a member of the opposite sex. Objects provide an inte- grated set of stimulus elements (color, shape, movement, etc.). Some of the stimulus elements of an object are initially behaviorally silent, whereas others may elicit behavior unconditionally. Through encounters with the object, the initially ineffective stimulus features may become associated with the unconditioned stimulus elements (Konorski, 1967).

Males may learn about the species-typical features of a female through object learning. A female quail provides an integrated set of distinctive stimuli (plumage pattern, body shape, movement, vocalizations). Initially, only some of these cues may be effective in eliciting copulatory behavior in male birds (perhaps movement cues and the shape and plumage of the female's body are critical). However, through repeated copulatory experiences, initially ineffective cues (such as visual cues of just the female's head and neck) might also come to elicit copulatory behavior through association with the unconditioned stimulus elements.

We tested the applicability of the object-learning model by providing male subjects with opportunities to copulate with a live female quail. The subjects were then tested with an inanimate model that contained only the head and neck of a female (Domjan et al., 1989). Members of one group of subjects were given the opportunity to copulate with a live female on 15 occasions in the same arenas in which they were tested later with the head + neck model. Members of a second group, while also receiving the 15 copulatory opportunities and being familiarized with the test arenas, were provided with the copulatory opportunities in their home cages, which were distinctively different from the test arenas. According to the object-learning hypothesis, copulation with live females should lead to association of the visual cues of the female's head and neck with copulatory reinforcement, regardless of where that copulatory experience takes place. Therefore, both groups were expected to learn to copulate with the head+neck model to the same extent.

The results contradicted the object-learning prediction. The spatial context in which the male birds received their sexual experience with live females proved to be critical. Copulation with the head + neck model was increased significantly more by sexual experience in the test cages than it was by sexual experience in the home cages. Evidently the contextual cues of the test cages became associated with copulatory opportunity, and the presence of these contextual conditioned stimuli increased the effectiveness of female head and neck plumage in eliciting copulatory behavior during the test sessions. These results illustrate modulation of the effectiveness of species-typical stimuli by conditioned contextual cues.

\section{ORGANIZATION OF THE STIMULUS DIMENSION OF THE CONDITIONED SEXUAL BEHAVIOR SYSTEM}

The available evidence suggests that three different categories of stimuli are important in sexual learning. 
We first considered conventional conditioned stimuli, such as a light and a buzzer (Domjan et al., 1986; Farris, 1967). Such stimuli are located in a particular place and may be considered to be arbitrary with respect to sexual behavior because they do not elicit any component of sexual behavior unconditionally. Other conditioned stimuli such as toys, wood blocks, and terrycloth objects may be included in this category because they are also localized and elicit no sexual behavior unconditionally. The second category of stimuli we encountered included various species-typical features of a female or male quail (e.g., plumage and shape). The third category of stimuli consisted of contextual cues of the arena in which the subjects received copulatory opportunity.

The three categories of stimuli (local arbitrary cues, species-typical cues, and more general contextual cues) are not entirely independent of each other. The physical relationships among the stimuli are illustrated in Figure 1. In our experiments, species-typical cues were usually provided by a female quail in an experimental arena. Thus, species-typical cues were embedded in contextual cues. This is represented in Figure 1 by having the set of species-typical cues appear as a subset of the contextual cues of the experimental arena. The local cues that we used (such as a light or a terrycloth object) were also presented in the experimental arena and therefore these are also represented in Figure 1 as a subset of contextual cues. In addition, the local cues were always presented near the door from which the stimulus female was released to provide copulatory opportunity. This is represented in Figure 1 by having the local cues next to the species-typical cues.

In addition to the physical relations that exist among the three categories of stimuli, the research results indicate that certain functional relations can be established among the stimuli through conditioning. These functional relations are illustrated by the arrows in Figure 1. The fact that a red-light conditioned stimulus can facilitate copulatory behavior elicited by a female quail (Domjan et al., 1986) is represented by Arrow \#1 in Figure 1 . The facilitation of copulatory behavior by conditioned contextual cues (Domjan et al., 1989; see also Domjan, Akins, \& Vandergriff, 1992) is illustrated by Arrow \#2. Finally, in other studies, we have found that contextual cues can also come to modulate the effectiveness of local cues in eliciting conditioned approach behavior (see Domjan, Akins, \& Vandergriff, 1992, for more details). This last finding is illustrated by Arrow $\# 3$ in Figure 1.

\section{CURRENT STATUS OF THE SEXUAL LEARNING BEHAVIOR SYSTEM}

As experimental evidence of sexual learning has accumulated, my research associates and I have attempted to formulate a behavior system that might characterize the results. The behavior system we currently envision has both a response dimension and a stimulus dimension. The response dimension consists of three categories:

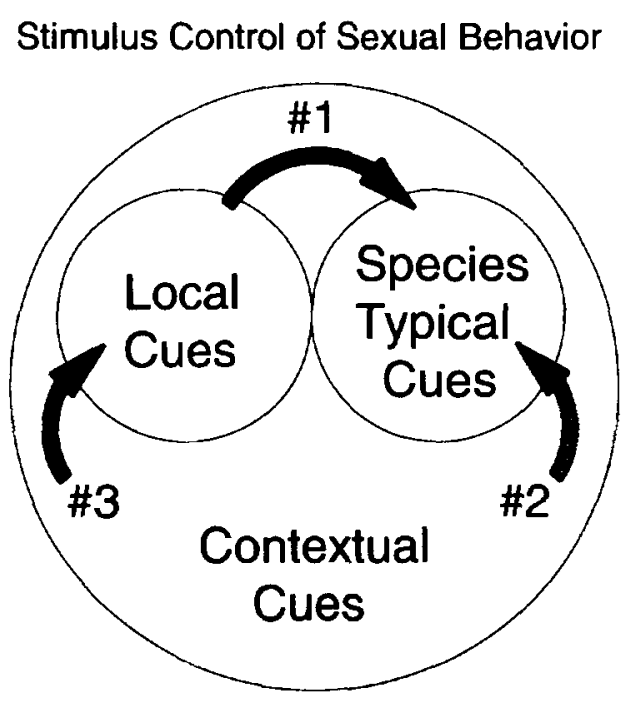

Figure 1. Relations among species-typical cues, local cues, and contextual cues in the sexual behavior system. The circles represent the physical relations among the three categories of cues; species-typical cues and local cues are physically close to each other and occur within broader contextual cues. The arrows illustrate the conditioned functional relations that can be established among the different types of stimuli; contextual and local cues can modulate the effectiveness of species-typical cues in eliciting sexual behavior (Arrows \#1 and \#2), and contextual cues can modulate the effectiveness of local cues (Arrow \#3).

general search behavior, focal search, and copulatory or consummatory behavior. The stimulus dimension likewise consists of three categories: species-typical stimuli, local cues, and contextual cues.

As with other behavior systems, some components of the system are assumed to be in place and organized before any learning experiences are introduced. The response profile for the sexual behavior system of the male quail before conditioning is illustrated in Figure 2 . In this response profile, the density of open circles in each quadrant represents the strength of control of a given type of behavior by the corresponding type of stimulus.

Let us first consider contextual cues. We presume that before conditioning, general contextual cues elicit general search behavior. Therefore, the unconditioned response profile has a number of open circles in the intersection of general search behavior and contextual cues. (Nonlocalized exploratory behavior would be in this cell of Figure 2.) General contextual cues are not likely to elicit focal search behavior; such behavior is more likely to be guided by localized stimuli. General contextual cues are also not likely to elicit copulatory responses unconditionally. Therefore, no symbols appear in Figure 2 in the intersections of contextual cues with focal search and with copulatory behavior.

Prior to sexual experience, arbitrary local cues have a status that is much like that of general contextual cues. Arbitrary local cues may elicit some general search behavior unconditionally. However, arbitrary local cues are 


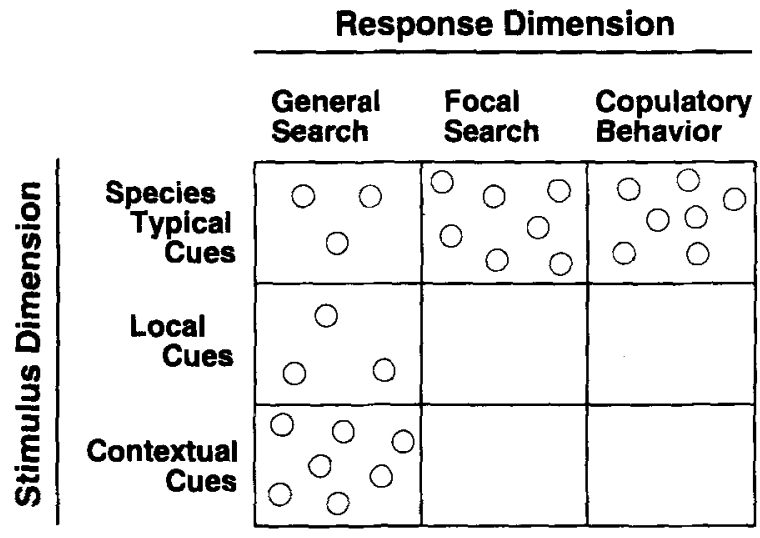

Figure 2. The response profile of the sexual behavior system before conditioning. The density of the open circles represents the degree of control of each type of stimulus over each type of response.

not likely to elicit focal search unless they have gained some special significance through association with sexual opportunity. Similarly, they cannot elicit copulatory or consummatory sexual responses unconditionally. Therefore, local cues are assumed to have relatively litthe behavioral effect before conditioning.

In contrast to contextual and local cues, speciestypical stimuli may elicit a variety of sexual responses unconditionally. For example, poorly localized vocalizations or rustlings of female quail in the underbrush may elicit general search behavior in male birds. More discretely localized auditory and visual cues provided by a female will elicit focal search behavior in the form of directed approach. Finally, once the female has been found, its plumage, shape, and movements can elicit copulatory responses.

The response profile for sexual behavior after conditioning is illustrated in Figure 3. After conditioning, sexual behavior reflects both conditioned and unconditioned effects. In the diagram, unconditioned effects are represented by the density of the open circles, while conditioned effects are represented by the density of the stars and by the arrows.

One obvious effect of conditioning is to increase the extent to which various components of sexual behavior are influenced by environmental stimuli. Conditioning serves to increase the range of stimuli that are effective in eliciting sexual responses. For example, conditioning enables local cues to elicit each component of the sexual-behavior sequence. Conditioning also establishes modulatory influences among stimuli. Through these changes, sexual behavior becomes more closely coordinated with environmental events.

Recapping the earlier review of the experimental evidence, the primary effect of pairing a local stimulus with copulatory opportunity is to condition focal search behavior to the local cues (e.g., Domjan et al., 1986). If the local cues provide the necessary supporting stimulation for copulatory responses, and if the stimuli are presented with species-typical cues that are only gradually removed, local cues can also come to elicit conditioned copulatory responses (Domjan, Huber-McDonald, \& Holloway, 1992). Finally, if local cues are conditioned with a long CS-US interval ( $20 \mathrm{~min}$ or more), they are likely to elicit responses akin to general search behavior (Akins et al., 1994). Thus, although the most easily established effect of sexual conditioning with local cues is the elicitation of focal search behavior, local cues can also come to elicit general search and copulatory responses under special circumstances. In addition to these direct effects of conditioned local cues, such stimuli can facilitate copulatory behavior elicited by a live female (Domjan et al., 1986). This modulatory influence is illustrated in Figure 3 by an arrow from the middle to the top row.

Sexually conditioned contextual cues appear to influence behavior primarily by facilitating responses elicited by other types of stimuli. Conditioned contextual cues facilitate copulatory behavior elicited by the shape and plumage of a female's head and neck (Domjan et al., 1989). Conditioned contextual cues also facilitate approach or focal search responses elicited by the sight of a female's plumage (Domjan, Akins, \& Vandergriff, 1992). These effects are illustrated in Figure 3 by arrows from the bottom to the top row. Finally, conditioned contextual cues can modulate focal search behavior elicited by conditioned local cues (Domjan, Akins, \& Vandergriff, 1992). This is illustrated in Figure 3 by the arrow from the bottom to the middle row.

With species-typical cues, we have identified only one direct effect of learning. Studies of how quail learn to distinguish the sex of other quail showed that males can learn directly about species-typical stimuli. This learning was evident in focal search behavior elicited by the sexually dimorphic plumage of the birds (e.g., Nash et al., 1989). Other studies showed that learning influences on the effectiveness of species-typical cues in elic-

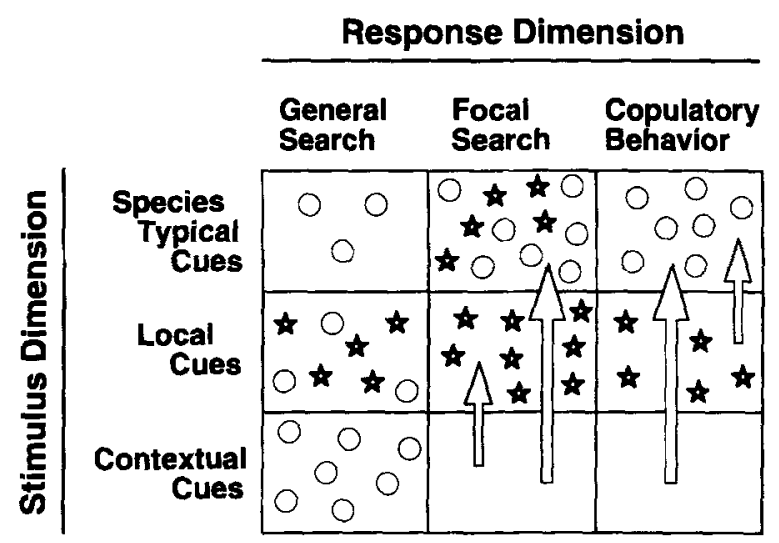

Figure 3. The response profile of the sexual behavior system after conditioning. The density of the open circles (unconditioned effects) and the stars (conditioned effects) represents the degree of control of each type of stimulus over each type of response. Arrows represent conditioned modulatory influences. 
iting sexual behavior are evident primarily in modulatory influences. As the end points of the arrows in Figure 3 illustrate, the effectiveness of species-typical cues in eliciting focal search behavior can be influenced by contextual cues (Domjan, Akins, \& Vandergriff, 1992), and the effectiveness of species-typical cues in eliciting copulatory behavior can be influenced by both contextual cues and conditioned local cues (Domjan et al., 1989; Domjan et al., 1986).

\section{DISCUSSION}

Although some of the studies from our laboratory have demonstrated that visual access to a female quail can be an effective unconditioned stimulus for sexual learning (Crawford \& Domjan, 1993; Holloway \& Domjan, 1993), all of the experiments that were reviewed in this paper involved copulatory access to a female quail as the unconditioned stimulus. Such an unconditioned stimulus invariably elicited approach and copulatory behavior. However, this uniformity of unconditioned behavior did not result in a uniformity of learning effects. Rather, sexual learning was evident in many different forms.

Under certain circumstances, a behavior akin to general search developed as the conditioned response; under other conditions, focal search behavior was acquired in response to the conditioned stimulus; and under yet other circumstances, conditioned copulatory behavior occurred. In addition to these effects, in many cases, conditioning did not result in the direct elicitation of any sexual responses. Rather, conditioning of one type of stimulus (contextual or local cue) increased the effectiveness of other types of cues (species-typical cues in most cases) in eliciting focal search or copulatory behavior.

The various phenomena that we have identified are certainly not without precedent in the learning literature. For example, sign tracking that can be conditioned with ingestional unconditioned stimuli may be considered a form of focal search behavior (see Tomie, Brooks, \& Zito, 1989, for a recent review), and conditioned drinking and eating responses observed in pigeons (Jenkins \& Moore, 1973) are forms of conditioned consummatory behavior. Other precedents for our findings include studies showing that in appetitive conditioning of laboratory rats, the topography of skeletal conditioned responses varies as a function of the conditioned stimulus (e.g., Holland, 1977) and the CS-US interval (Holland, 1980). Finally, modulatory effects of conditioned stimuli have been previously demonstrated in a variety of appetitive and aversive conditioning preparations (e.g., Brandon \& Wagner, 1991; Holland, 1992).

As I indicated at the outset, we pursued a primarily synthetic research strategy, guided loosely by basic Pavlovian conditioning concepts. Therefore, we were prepared to find modulatory conditioning effects and differences in the conditioning of local search and consummatory sexual behavior. However, nothing in the conventional Pavlovian conditioning literature led us to predict that the nature of the conditioned response would shift from CS-directed behavior to more general search behavior as the CS-US interval was extended from 1 to $20 \mathrm{~min}$

Several theoretical approaches have been proposed to explain the various types of conditioned responses that develop as a result of Pavlovian conditioning. Konorski (1967), for example, distinguished between the conditioning of preparatory and consummatory responses. Preparatory and consummatory responses in Konorski's model are similar to appetitive and consummatory behavior in classical ethology. Our research suggests that the appetitive or preparatory response category in fact consists of two functionally distinct types of behaviornamely, general search and focal search. In addition, our results indicate that different CS-US intervals are required to condition different forms of conditioned behavior. In contrast, Konorski assumed that "the indispensable condition for the formation of every association" is CS-US contiguity (Konorski, 1967, p. 292).

More recently, Lennartz and Weinberger (1992) provided a characterization of defensive Pavlovian conditioned responses based on an extensive review of the literature. They concluded that different forms of conditioned behavior reflect different stages of conditioning. During the initial stage of conditioning, subjects are assumed to learn a CS-US association, which is manifest in a conditioned response (such as a change in heart rate) that is not specific to the US employed. With additional conditioning trials, a more US-specific conditioned response is assumed to develop (e.g., the nictitating membrane response). According to this formulation, the form of the conditioned response is assumed to be a function of the extent of conditioning. In our model, different conditioned responses are assumed to develop as a function of different conditioned stimuli and CS-US intervals. In contrast, Lennartz and Weinberger specifically rejected the nature of the CS or the CS-US interval as critical determinants of the form of the conditioned response.

As our findings accumulated, we looked for ways to organize and systematize the findings that went beyond the types of models that were proposed by Konorski (1967) and Lennartz and Weinberger (1992). The behavior system we formulated was constructed to fit the facts. Thus, the model is post hoc and served initially as a description and systematization of the diverse set of findings.

The behavior system model can now be used to generate new research questions. The model represented in Figure 3 summarizes the learning effects that we have investigated but does not represent all of the learning phenomena that may exist in the sexual behavior system. For example, we do not know whether contextual cues associated with copulatory opportunity could elicit general search behavior directly. Figure 3 also allows for various additional modulatory effects that have yet to be investigated. For example, we do not know whether con- 
ditioned contextual cues can modulate copulatory behavior conditioned to local cues. We also do not know whether conditioned local cues can modulate focal search behavior elicited by species-typical cues. Much has yet to be learned about the mechanisms of modulatory effects and why some learning effects are manifest in modulatory influences rather than in direct conditioned responses. Finally, Figure 3 does not represent any inhibitory influences that may be involved in sexual learning phenomena.

\section{REFERENCES}

ADKINS-REGAN, E. (1983). Sex steroids and the differentiation and activation of avian reproductive behaviour. In J. Balthazart, E. Pröve, \& R. Gilles (Eds.), Hormones and behaviour in higher vertebrates (pp. 218-228). Berlin: Springer-Verlag.

AKIns, C. A., DomJan, M., \& GutiérRez, G. (1994). Topography of sexually conditioned behavior in male Japanese quail (Coturnix japonica) depends on the CS-US interval. Journal of Experimental Psychology: Animal Behavior Processes, 20, 199-209.

BalthazarT, J. (1990). Aromatization of testosterone in the preoptic area and control of male sexual behavior in the Japanese quail. In M. Wada, S. Ishii, \& C. G. Scanes (Eds.), Endocrinology of birds (pp. 297-311). Berlin: Springer-Verlag.

Balthazart, J., \& Schumacher, M. (1984). Organization and activation of behavior in quail: Role of testosterone metabolism. Journal of Experimental Zoology, 232, 595-604.

BalthazarT, J., \& Schumacher, M. (1985). Role of testosterone in the activation of sexual behaviour in birds. In R. Gilles \& J. Balthazart (Eds.), Neurobiology: Current comparative approaches (pp. 121-140). Berlin: Springer-Verlag.

BRANDON, S. E., \& WAGNER, A. R. (1991). Modulation of a discrete Pavlovian conditioned reflex by a putative emotive Pavlovian conditioned stimulus. Journal of Experimental Psychology: Animal Behavior Processes, 17, 299-311.

Crawford, L. L., \& Akins, C. A. (1993). Stimulus control of copulatory behavior in male Japanese quail. Poultry Science, 72, 722-727.

Crawford, L. L., \& Domjan, M. (1993). Sexual approach conditioning: Omission contingency tests. Animal Learning \& Behavior, 21, 42-50.

Domjan, M. (1990). The modification of sexual behavior through conditioning: An avian model. In J. R. Feierman (Ed.), Pedophilia: Biosocial dimensions (pp. 242-273). New York: Springer-Verlag.

Domjan, M., Akins, C., \& VANdergriff, D. H. (1992). Increased responding to female stimuli as a result of sexual experience: Tests of mechanisms of learning. Quarterly Journal of Experimental Psychology, 45B, 139-157.

Domjan, M., GreEne, P., \& North, N. C. (1989). Contextual conditioning and the control of copulatory behavior by species-typical sign stimuli in male Japanese quail. Journal of Experimental Psychology: Animal Behavior Processes, 15, 147-153.

Domian, M., \& HALL, S. (1986). Determinants of social proximity in Japanese quail (Coturnix coturnix japonica): Male behavior. Journal of Comparative Psychology, 100, 59-67.

Domjan, M., \& Hollis, K. L. (1988). Reproductive behavior: A potential model system for adaptive specializations in learning. In R. C. Bolles \& M. D. Beecher (Eds.), Evolution and learning (pp. 213-238). Hillsdale, NJ: Erlbaum.

Domjan, M., Huber-MCDonald, M., \& Holloway, K. S. (1992). Conditioning copulatory behavior to an artificial object: Efficacy of stimulus fading. Animal Learning \& Behavior, 20, 350-362.
Domjan, M., Lyons, R., North, N. C., \& Bruell, J. (1986). Sexual Pavlovian conditioned approach behavior in male Japanese quail (Coturnix coturnix japonica). Journal of Comparative Psychology, $100,413-421$

Domjan, M., O'VARY, D., \& GReEne, P. (1988). Conditioning of appetitive and consummatory sexual behavior in male Japanese quail. Journal of the Experimental Analysis of Behavior, 50, 505-519.

Domjan, M., \& RaverT, R. D. (1991). Discriminating the sex of conspecifics by male Japanese quail (Coturnix coturnix japonica). Journal of Comparative Psychology, 105, 157-164.

EIBL-EIBESFELDT, I. (1970). Ethology: The biology of behavior. (E. Klinghammer, Trans.). New York: Holt, Rinehart \& Winston.

FARRIS, H. E. (1967). Classical conditioning of courting behavior in the Japanese quail, Coturnix coturnix japonica. Journal of the Experimental Analysis of Behavior, 10, 213-217.

Holland, P. C. (1977). Conditioned stimulus as a determinant of the form of the Pavlovian conditioned response. Journal of Experimental Psychology: Animal Behavior Processes, 3, 77-104.

Holland, P. C. (1980). CS-US interval as a determinant of the form of Pavlovian appetitive conditioned responses. Journal of Experimental Psychology: Animal Behavior Processes, 6, 115-174.

Holland, P. C. (1992). Occasion setting in Pavlovian conditioning. In D. L. Medin (Ed.), The psychology of learning and motivation (Vol. 28, pp. 69-125). Orlando, FL: Academic Press.

Holloway, K. S., \& Domjan, M. (1993). Sexual approach conditioning: Unconditioned stimulus factors. Journal of Experimental Psychology: Animal Behavior Processes, 19, 38-46.

JENKINS, H. M., \& MoORE, B. R. (1973). The form of the autoshaped response with food or water reinforcers. Journal of the Experimental Analysis of Behavior, 20, 163-181.

KöKsal, F., Domuan, M., \& Weisman, G. (1994). Blocking of the sexual conditioning of differentially effective conditioned stimulus objects. Animal Learning \& Behavior, 22, 103-111.

KONORSKI, J. (1967). Integrative activity of the brain. Chicago: University of Chicago Press.

KovaCH, J. K. (1974). The behaviour of Japanese quail: Review of literature from a bioethological perspective. Applied Animal Ethology, $1,77-102$.

LenNartZ, R. C., \& Weinberger, N. M. (1992). Analysis of response systems in Pavlovian conditioning reveals rapidly versus slowly acquired conditioned responses: Support for two factors, implications for behavior and neurobiology. Psychobiology, 20, 93-119.

Nash, S., \& Domuan, M. (1991). Learning to discriminate the sex of conspecifics in male Japanese quail (Coturnix coturnix japonica): Tests of "biological constraints." Journal of Experimental Psychology: Animal Behavior Processes, 17, 342-353.

Nash, S., Domjan, M., \& Askins, M. (1989). Sexual discrimination learning in male Japanese quail (Coturnix coturnix japonica). Journal of Comparative Psychology, 103, 347-358.

TimberLAKE, W., \& LuCAS, G. A. (1989). Behavior systems and learning: From misbehavior to general principles. In S. B. Klein \& R. R. Mowrer (Eds.), Contemporary learning theories: Instrumental conditioning theory and the impact of biological constraints on learning (pp. 237-275). Hillsdale, NJ: Erlbaum.

TiNBERGEN, N. (1951). The study of instinct. Oxford: Oxford University Press, Clarendon Press.

TOMIE, A., Brooks, W., \& Zito, B. (1989). Sign-tracking: The search for reward. In S. B. Klein \& R. R. Mowrer (Eds.), Contemporary learning theories: Pavlovian conditioning and the status of learning theory (pp. 191-223). Hillsdale, NJ: Erlbaum.

(Manuscript received November 19, 1993; revision accepted for publication June 13, 1994.) 